OPEN ACCESS

\section{Hard X-ray measurement from a plasma focus of low energy}

To cite this article: Patricio Silva et al 2008 J. Phys.: Conf. Ser. 134012045

View the article online for updates and enhancements.
You may also like

$$
\begin{aligned}
& \text { - Uncertainty estimation and statistical } \\
& \text { comparative methodology for } \\
& \text { mammography x-ray energy spectra } \\
& \text { V Santoro-Fernandes, J C Santos, L } \\
& \text { Mariano et al. } \\
& \text { - Effect of discharge polarity on OH density } \\
& \text { and temperature in coaxial-cylinder barrier } \\
& \text { discharge under atmospheric pressure } \\
& \text { humid air } \\
& \text { Yusuke Nakagawa, Ryo Ono and Tetsuji } \\
& \text { Oda }
\end{aligned}
$$

Synthesis and characterization of grinding aid fly ash blended mortar effect on bond strength of masonry prisms

L Krishnaraj, P T Ravichandran and Suresh Sagadevan
The Electrochemical Society

Advancing solid state \& electrochemical science \& technology

243rd Meeting with SOFC-XVIII

Boston, MA • May 28 - June 2, 2023

Accelerate scientific discovery!
Learn More \& Register

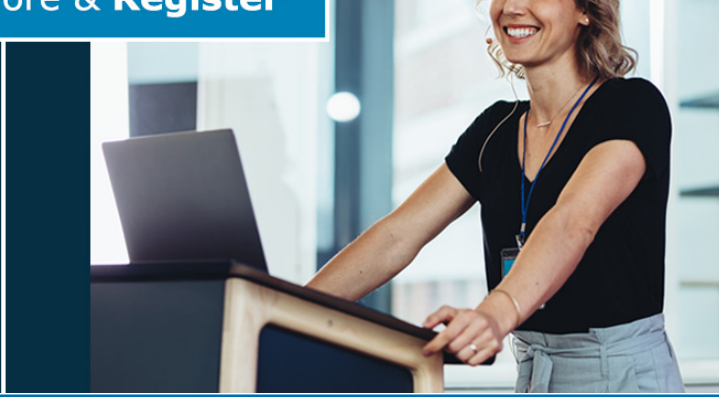

This content was downloaded from IP address 3.89.197.203 on 26/04/2023 at 00:30 


\title{
Hard X-Ray Measurement from a Plasma Focus of Low Energy
}

\author{
Patricio Silva ${ }^{1}$, Cristián Farías ${ }^{2}$, Patricio L’Huissier ${ }^{2}$, Victor Pinto ${ }^{2}$, Marcelo \\ Zambra $^{1}$ and Leopoldo Soto ${ }^{1}$ \\ ${ }^{1}$ Comisión Chilena de Energía Nuclear, Casilla 188-D, Santiago, Chile \\ ${ }^{2}$ Universidad de Chile, Facultad de Ciencias, Departamento de Física, Santiago, Chile \\ E-mail: mzambra@cchen.cl
}

\begin{abstract}
Hard X-ray emission in the plasma focus device PF-400J [1-3] is studied using a stepped filters array of different materials and thickness leaned to a radiographic commercial cassette, Agfa Curix [4, 5]. This diagnostic is located in the axial symmetrical axis at $45 \mathrm{~cm}$ away from pinch zone. Different targets are used $(\mathrm{Cu}, \mathrm{Mo}, \mathrm{Ag}, \mathrm{Pb})$ at the bottom of the central hole of the anode. The device was run using Hydrogen like filling gas at a charging voltage between $28 \mathrm{kV}$ to $30 \mathrm{kV}$. Accumulating $\mathrm{X}$ radiation over a X-ray film by means of a sequence of electrical discharges, effective energies are obtained whose values are between $30 \mathrm{keV}$ to close $100 \mathrm{keV}$. The obtained energy is discussed and interpreted like an effective energy, when it is compared with the results that would be obtained by means of X-ray generators based on a conventional accelerator. X-ray photographies of organic bodies are obtained showing possible applications.
\end{abstract}

\section{Introduction}

Pulsed plasmas, generated by a transient gas electrical discharge, such as plasma focus or Z-pinch, are an attractive high-intensity and very short duration X-ray source. These kind of sources have important additional merits: high efficiency, operational simplicity, long life, compact size, and low cost.

Particularly, the plasma focus (PF) is a kind of pinch discharge in which a high pulsed voltage is applied over a low-pressure gas using a coaxial cylindrical electrode system. The central electrode is the anode and it is partially covered with a coaxial insulator. In the pinch phase, a plasma column is produced due to magnetic confinement and during its collapse generates pulsed emissions of (i) ions and electrons beam, (ii) X-rays $(<100 \mathrm{~ns})$, and (iii) neutrons (using Deuterium gas). Normally, the $\mathrm{X}$-ray energy have a wide emission range, from close to $1 \mathrm{keV}$ to more than $100 \mathrm{keV}$.

So, the principal aim of this work is to characterize the spectral hard X-ray emission and its potential practical applications when different targets, in the anode, are used in the plasma focus PF400J. The principal characteristic of the PF-400J - designed and constructed in the Thermonuclear Plasma Department of the Comisión Chilena de Energía Nuclear - is its short rise time ( $\sim 300 \mathrm{~ns})$ and low energy $(<1$ kJoule). 


\section{Experimental Setup}

The experiments were performed in the PF-400J plasma focus device: $880 \mathrm{nF}, 40 \mathrm{nH}, 20-35 \mathrm{kV}, 94-$ $160 \mathrm{kA}, 176-539 \mathrm{~J}$, rise time $\sim 300 \mathrm{~ns}$, and repetition rate of $0.1 \mathrm{~Hz}$.. A charging voltage between 28 $\mathrm{kV}$ to $30 \mathrm{kV}$ (345 to $400 \mathrm{~J}$ ), and Hydrogen gas at pressures between 8 to 10 mbar were used. Voltage signal is measured at the base of the anode by a voltage divider, and current signal is obtained by means a Rogowski coil coupled to the capacitor bank. To study the hard X-ray emission, alternatively four different targets were located inside of the hollow anode: Copper, Silver, Molybdenum and Lead.

The X-ray image is impress in a commercial radiographic film, Agfa Curix ST-G2 $\left(13 \times 18 \mathrm{~cm}^{2}\right)$, placed inside a plastic light tight cassette, Curix from AGFA, containing an intensifier plastic X-ray sensitive screen. The objects, to be imaged, were placed axially outside the stainless steel chamber between the pinch region and the cassette, at $45 \mathrm{~cm}$ away from the upper side of the anode. The obtained image films are scanned with a resolution of 300 dpi using the HP ScanJet 5530 scanner.

A photomultiplier tube Photonis XP2262b (5 cm diameter, $5 \mathrm{~cm}$ long) with a BC400 plastic scintillator are used to monitor the X-ray emission in each shot. This diagnostic is placed perpendicularly to the symmetry axis at $2.25 \mathrm{~cm}$ of the anode top level.

Due to the low emission of the PF-400J it is necessary to accumulate the X-ray emision, coming from several discharges, over the same radiographic film. A minimum level, in the intensity of the photomultiplier signal, is necessary to obtain good contrast radiography. Principally, X-ray emission that produce a voltage signal photomultiplier over this threshold value $(2.6 \mathrm{~V})$ allows a well-down analyze of the radiographic film.

\section{X-Ray Effective Energy}

The method to determine the effective energy of the X-rays is based on the well-known relation for radiation decay through the matter: $I(x)=I_{0} \cdot e^{-\mu(E) \cdot x}$, where $\mu$ is the linear attenuation coefficient for a given material and $x$ is the penetration depth photons of energy $E$. Assuming a continuous energy spectrum and integrating over $E$, an effective attenuation coefficient $\mu^{*}$ can be obtained from the quotient $I_{T}(x) / I_{O T}=\cdot e^{-\mu \cdot x}$, where $I_{O T}$ is the total intensity of the incident beam, and $I_{T}(x)$ is the total intensity of the beam passing through the material of thickness $x$. Now, if $\mu^{*}$ is a well-known value then the effective energy $E^{*}$ can be estimated from the $\mu(E)$ data. This energy $\left(E^{*}\right)$ can be interpreted like the energy that would have a monochromatic beam to reproduce the same quotient of intensities.

Assuming a linear relation between the grey level of a radiograph, $N$, and the radiation intensities ratio, $I_{T}(x) / I_{O T}$, it is possible to obtain an experimental value by means of the equation $I_{T}(x) / I_{0 T}=\left(N_{\max }\right.$ $N(x)) /\left(N_{\max }-N_{\min }\right)$, where $N_{\max }$ and $N_{\min }$ correspond to the minimun and maximun blackenning of the film respectively.

By using a stepped filters array of different single elements, it can be obtain the quotient for each $x$ thickness and plotting $\operatorname{Ln}\left(I_{T}(x) / I_{O T}\right)$ against $x$ the $\mu^{*}$ value is obtained from the slope of the waited straight line.

The different thickness of the elements used like stepped filters are shown in the Table I; where the Lead is used to verify the threshold of "non-irradiation" level.

Table I

Materials and thickness of steeped filters used

\begin{tabular}{|l|lllllllll|}
\hline \hline Element & \multicolumn{10}{|l|}{ Thickness (mm) } \\
\hline \hline $\mathrm{PB} \mathrm{1}$ & 2.40 & 4.80 & 7.20 & 9.60 & & & & & \\
$\mathrm{Cd}$ & 0.25 & 0.50 & 0.75 & 1.00 & 1.25 & 1.50 & 1.75 & & \\
$\mathrm{Ag}$ & 0.25 & 0.50 & 0.75 & 1.00 & 1.25 & 1.50 & & & \\
$\mathrm{Mo}$ & 0.25 & 0.50 & 0.75 & 1.00 & 1.25 & & & & \\
$\mathrm{Cu} 1$ & 0.10 & 0.20 & 0.30 & 0.40 & 0.50 & 0.60 & 0.70 & 0.80 & 0.90 \\
$\mathrm{Cu} 2$ & 0.20 & 0.40 & 0.60 & 0.80 & 1.00 & 1.20 & 1.40 & 1.60 & 1.80 \\
$\mathrm{~Pb} 2$ & 1.60 & 3.20 & 4.80 & & & & & & \\
\hline \hline
\end{tabular}




\section{Experimental Results}

Figure 1 shows the typical digital computer image of the stepped filter radiography obtained after a shots sequence. Table II shows the effective energy for the different targets and it is indicated the accumulated shots number with an out voltage photomultiplier $\left(\mathrm{V}_{\mathrm{FM}}\right)$ greater than $2.6 \mathrm{~V}$. Additionally, typical radiographies of stepped filters and a seed pot are showed in the Fig. 1 and Fig 2 respectively.

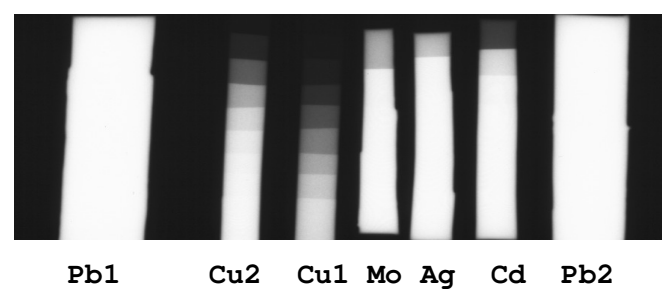

Figure 1: Typical digital computer image of a radiographic film obtained after a shots sequency.

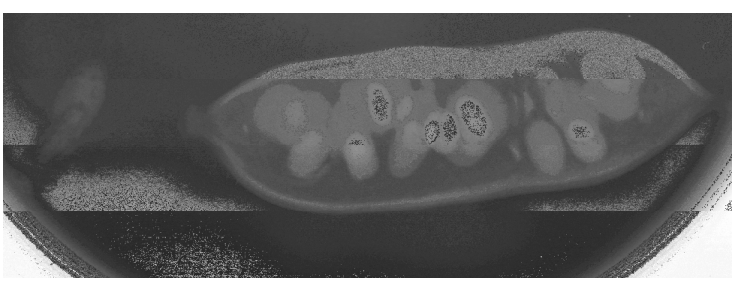

Figure 2: radiographic image of a pod seed.

Table II

Effective energy for different targets against the accumulated shots number

\begin{tabular}{|c|c|c|c|c|}
\hline \multirow[b]{2}{*}{ ID Plate } & \multicolumn{2}{|c|}{ Target } & \multirow{2}{*}{$\begin{array}{c}\text { Number of shots } \\
\mathrm{V}_{\mathrm{FM}}>2.6 \mathrm{~V}\end{array}$} & \multirow[b]{2}{*}{$\mathrm{E}^{*} \quad(\mathrm{keV})$} \\
\hline & $\begin{array}{c}\text { Elemen } \\
t\end{array}$ & z & & \\
\hline V160606-03 & \multirow{3}{*}{$\mathrm{Cu}$} & \multirow{3}{*}{29} & 1 & $33 \pm 1$ \\
\hline V160606-02 & & & 4 & $51 \pm 3$ \\
\hline V160606-01 & & & 4 & $55 \pm 3$ \\
\hline V090606-01 & \multirow{6}{*}{ Mo } & \multirow{6}{*}{42} & 5 & $51 \pm 2$ \\
\hline V090606-06 & & & 7 & $56 \pm 1$ \\
\hline V090606-07 & & & 6 & $56 \pm 1$ \\
\hline V090606-02 & & & 10 & $69 \pm 7$ \\
\hline V090606-03 & & & 17 & $74 \pm 7$ \\
\hline $\begin{array}{c}\text { V090606- } \\
05\end{array}$ & & & 21 & $77 \pm 5$ \\
\hline $\begin{array}{c}\text { M2006 } 06- \\
01\end{array}$ & \multirow{6}{*}{ Ag } & \multirow{6}{*}{47} & 5 & $48 \pm 2$ \\
\hline $\begin{array}{c}\text { V230606- } \\
05\end{array}$ & & & 1 & $54 \pm 3$ \\
\hline $\begin{array}{c}\text { M200606- } \\
02\end{array}$ & & & 10 & $75 \pm 5$ \\
\hline $\begin{array}{c}\text { M200606- } \\
03\end{array}$ & & & 19 & $79 \pm 5$ \\
\hline $\begin{array}{c}\text { V230606- } \\
07\end{array}$ & & & 28 & $93 \pm 9$ \\
\hline $\begin{array}{c}\text { M200606- } \\
04\end{array}$ & & & 28 & $97 \pm 9$ \\
\hline $\begin{array}{c}\text { V230606- } \\
11 \\
\end{array}$ & \multirow{2}{*}{$\mathrm{Pb}$} & \multirow{2}{*}{82} & 1 & $44 \pm 1$ \\
\hline $\begin{array}{c}\text { V230606- } \\
13\end{array}$ & & & 8 & $90 \pm 8$ \\
\hline
\end{tabular}




\section{Discussion and Conclusions}

In plasma focus devices, the main source of hard X-ray come of the electrons beam interaction, coming from the focus region, with the anode or with a target inside of the anode hollow. For a nearly monoenergetic electrons beam, a combination of Bremsstrahlung and characteristic target radiation is obtained; in this case, the energy spectrum is limited by the electron beam energy. The effective energy obtained with the described method could be used for radiographic applications, but its relation with the source spectrum is not clear. To clarify this topic, the effective energy of a conventional Xray tube was measured. A Phillips tube, model YTU 320D03, with a tungsten target at an angle of $20^{\circ}$, and a $3 \mathrm{~mm}$ nominal inherent filter of Berylium was used. To accelerate the electrons beam, a potential of $50 \mathrm{kV}$ was applied with a radiation exposure of $100 \mathrm{mRem}$ over the cartridge and filters. An effective energy of $42 \mathrm{keV}$ was obtained. Using a simple model for to determine the spectrum, that energy is located close to spectrum tail. In the case of the experiment in the PF-400J device, the effective energy value grows against the number of accumulated shots for each target (Table II), and this one fluctuates between $30 \mathrm{keV}$ and $100 \mathrm{keV}$ approximately. The relative higher atomic number of the lead target favors the higher effective energy appearance for a low accumulated shots number $\left(E^{*}\right.$ $=90 \mathrm{keV}$ at only 8 shots). This accumulative phenomenun is not observed in a PF with higher energy, because the obtained radiographies have needed only one shot. On the other hand, if the obtained spectrums are approximately similar for different shots, it would be waited just one effective energy value - independently of the accumulated shots number - for a specific target. Clearly, this does not correspond to the obtained result. This difference could be attributed to a low intensity emission for the highest energy photons in the spectrum. In this case, the film in the radiographic cassette would not register all the energy components of the spectrum. Then, it is necessary to accumulate a higher number of shots to observe the complete spectrum. This shots accumulation implicate an increase of the effective energy, and it would increase until it reaches a maximum, when the complete spectrum was being observed in the film. Just for that maximum effective energy value, it could be said that this energy value is the right value and it would find in the spectrum tail like it observed for the conventional X-ray tube case.

With respect to the images, the obtained results are preliminary, but it is observed that only the targets of Mo and Ag, within the used ones, are the most useful for radiographic applications of organic bodies.

In the next experimental works new measurements will become in order to verify the proposed explanation, about the effective energy against the accumulated shots, as much in the PF-400J as in the conventional X-ray tube.

\section{Acknowledgments}

Research supported by FONDECYT grants 1040231 and by the CCHEN project 616.

\section{References}

[1] L. Soto, Plasma Physics and Controlled Fusion 47, A361 (2005)

[2] P. Silva, L. Soto, W. Kies, J. Moreno, Plasma Sources Sci. Technol. 13 (2004).

[3] P. Silva, J. Moreno, L. Soto, L. Birstein, R. E. Mayer, and W. Kies, Appl. Phys. Lett. 83, 3269 (2003).

[4] C. Moreno, M. Vénere, R.Barbuzza, M. Del Fresno, R. Ramos, H. Bruzzone, F.P.J. González, A. Clausse, Brazilian Journal of Physics, vol.32, $\mathrm{n}^{\circ} 1$ (2002).

[5] V. Raspa, "Estudio de un equipo Plasma Focus como emisor de rayos x de alta energía y su aplicación a radiografías no convencionales“ Tesis de Licenciatura. Depto de Física, FCEyN UBA, 2004. 